\title{
Efficacy and safety of percutaneous nephrolithotomy (PCNL): a prospective and randomized study comparing regional epidural anesthesia with general anesthesia
}

\author{
T. Tangpaitoon, C. Nisoog, B. Lojanapiwat \\ Division of Urology, Department of Surgery (TT, BL) and Department of Anesthesiology (CN) Faculty \\ of Medicine, Chaing Mai University, Thailand
}

\section{ABSTRACT}

Objective: To compare the efficacy and safety of regional epidural anesthesia and general anesthesia in patients who underwent PCNL.

Materials and Methods: Fifty patients submitted to percutaneous nephrolithotomy (PCNL) were randomized into two groups: Group I $(\mathrm{N}=26)$ received general anesthesia and Group II $(\mathrm{N}=24)$ received regional epidural anesthesia. Demographic and operative data including age, BMI, stone position, stone size, postoperative pain, amount of postoperative analgesic usage, length of hospital stay, patient satisfaction, preoperative and postoperative hemoglobin and hematocrit, adverse effects and surgical complications were compared between both groups.

Results: Average pain score at 1 hour. was 6.88 in group I and 3.12 in group II ( $p<$ $0.001)$, at 4 hours. 5.07 in group I and 3.42 in group II ( $p=0.025)$. Less morphine was required in the regional epidural anesthesia group compared to the general anesthesia group. Higher satisfaction was found in the regional epidural group. 6 (23.07\%) patients in Group I and 1 patient (4.19\%) in Group II had postoperative nausea and vomiting, respectively ( $\mathrm{p}=0.05$ ). Pain score at 12 hours, 24 hours, 48 hours, 72 hours, preoperative and postoperative hemoglobin and hematocrit, length of hospital stay, and adverse effects were no different between the two groups.

Conclusion: Regional epidural anesthesia is an alternative technique for PCNL which achieves more patient satisfaction, less early postoperative pain and less adverse effects from medication with the same efficacy and safety compared to general anesthesia.
ARTICLE INFO

\section{Key words:}

Nephrostomy, Percutaneous;

Anesthesia, General

Int Braz J Urol. 2012; 38: 504-11

Submitted for publication:

January 31, 2012

Accepted after revision:

May 22, 2012

\section{INTRODUCTION}

Percutaneous nephrolithotomy (PCNL) is the treatment of choice for large renal calculi, staghorn calculi and calculi which fail treatment with extracorporeal shockwave lithotripsy and ureteral endoscopy (1-3). PCNL can be performed under general anesthesia, regional anesthesia or local anesthesia. Nowadays, PCNL is usually performed under general anesthesia due to bet- ter control of breathing and more comfort for the patients. However, there are some occasionally side effects from general anesthesia such as lung atelectasia, drug allergy and postoperative nausea and vomiting $(4,5)$. Recently, PCNL under epidural anesthesia was reported as having some advantage over general anesthesia, such as lower post operative pain, lower dose requirement for analgesic drugs, and avoidance of the side effects from multiple medication during general anesthe- 
sia (4-6). The aim of this study was to compare the efficacy and safety of regional epidural anesthesia and general anesthesia in patients who underwent PCNL.

\section{MATERIALS AND METHODS}

\section{Patients}

Between September 1, 2010 to April 30, 2011, 50 patients submitted to PCNL were block randomized into two groups. Group I consisted of 26 patients who underwent PCNL under general anesthesia, Group II consisted of 24 patients $(\mathrm{N}=$ 24) who underwent PCNL under regional epidural anesthesia. All patients were operated on by one surgeon (Lojanapiwat B) and one anestheologist (Nisoog C). The exclusion criteria were uncontrolled medical illness such as severe cardiac disease, severe respiratory disease and patients with any contraindications for regional anesthesia including uncorrectable coagulopathy, high intracranial pressure and vertebral deformity.

Patients' demographic data were compared between both groups. The hemodynamic status, anesthetic parameters and any adverse events following general anesthesia and regional anesthesia were recorded before, during and after operation. The analog pain score at 1 hour, 4 hours, 12 hours, 24 hours, 48 hours, and 72 hours. after the operation was recorded by the research nurse. $3 \mathrm{mg}$ of morphine sulphate was intravenously administered when patients had a pain score of more than 6 points. Patients were interviewed at discharge and their satisfaction with treatment was recorded.

\section{Methods}

Patients in the general anesthesia group were induced with thiopental $(5 \mathrm{mg} / \mathrm{kg}$ ) and fentanyl $(1 \mathrm{mg} / \mathrm{kg})$, paralyzed with vecuronium $(0.1 \mathrm{mg} / \mathrm{kg})$ before endotracheal intubation and maintained on anesthesia with nitrous oxide in a mixture of 50\% oxygen and isoflurane (1-1.5\%). The regional epidural group was induced with a continuous infusion of chirocine ( $5 \mathrm{~mL} /$ hour) into the epidural space between L 1-2 level and their level of anesthesia was checked during the operation while they were sedated with intravenous proposal. Cystoscopy was performed to place a ureteric catheter into the upper ureter or renal pelvis. Renal access was performed in the prone position under fluoroscopic guidance. The access tract was dilated with an Amplatz dilator or telescopic metal dilator to $30 \mathrm{Fr}$ at which point the Amplatz sheath was placed. A 24 Fr nephroscope was introduced to the collecting system and the stone was disintegrated with ultrasonic or pneumatic lithotripter. The stone was removed by forceps and a nephrostomy tube was placed except for 5 patients whose stone was freed with no major bleeding or extravasation (tubeless PCNL).

The statistical analysis was carried out using SPSS statistic Chi-square and student t-test, using Software STATA version 11. A p-value < 0.05 was considered significant.

The protocol and other documents for this study were reviewed and approved by the ethics committee (Institutional Review Board) of the Faculty of Medicine, Chiang Mai University.

\section{RESULTS}

The mean age was $56.69 \pm 11.32$ and $53.04 \pm 13.53$ years old in Group I and Group II, respectively. Mean BMI of Group I was 21.36 $\pm 3.98 \mathrm{~kg} / \mathrm{m} 2$ and $21.25 \pm 3.21 \mathrm{~kg} / \mathrm{m} 2$ in Group II. Mean stone size was $3.54 \pm 1.07$ (range 2.0 to 5.7) in Group I, and $4.08 \pm 1.37$ (range 2.1 to 5.9) $\mathrm{cm}$ in Group II. Most patients received supracostal upper pole access. The patients' profile, stone position and stone size are shown in Table-1. Access tract, numbers of tubeless PCNL and success rates are shown in Table-2.

Mean preoperative and postoperative 24 hours hemoglobin and hematocrit levels in both Groups are shown in Table-3. A higher satisfaction score (level 4,5) was found in the regional epidural group. Patients with epidural anesthesia needed smaller amounts of postoperative analgesic drug. A reduced analog pain score in regional epidural anesthesia was found at 1 hour and 4 hours postoperatively (Table-4, Figure-1). Patients who underwent PCNL with general anesthesia received more analgesic drugs (Table-5).

Blood transfusion and complications showed no differences between both groups, but 
Table 1 - Patient's profile.

\begin{tabular}{|c|c|c|c|}
\hline Variable & $\mathrm{GA}(\mathrm{n}=26)$ & $\mathrm{RA}(\mathrm{n}=24)$ & $p$-value \\
\hline \multicolumn{4}{|l|}{ Sex } \\
\hline Male & 16 & 17 & 0.488 \\
\hline Female & 10 & 7 & \\
\hline \multicolumn{4}{|l|}{ Age (years) } \\
\hline Mean(SD) & $56.69 \pm 11.32$ & $53.04 \pm 13.53$ & 0.305 \\
\hline \multicolumn{4}{|l|}{ BMI (kg/sq.m) } \\
\hline Mean(SD) & $21.36 \pm 3.98$ & $21.25 \pm 3.21$ & 0.914 \\
\hline \multicolumn{4}{|l|}{ ASA, $n(\%)$} \\
\hline 1 & 7 (26.92) & $10(41.67)$ & 0.533 \\
\hline 2 & $18(69.23)$ & $13(54.17)$ & \\
\hline 3 & $1(3.85)$ & $1(4.17)$ & \\
\hline \multicolumn{4}{|l|}{ Side } \\
\hline Rt & 17 & 15 & 0.832 \\
\hline Lt & 9 & 9 & \\
\hline Stone size (cm) & $3.54 \pm 1.50$ & $4.08 \pm 1.64$ & 0.129 \\
\hline \multicolumn{4}{|l|}{ Stone position, $\mathrm{n}(\%)$} \\
\hline Staghorn stone & $9(34.62)$ & $10(41.67)$ & 0.349 \\
\hline Pelvic stone & $5(19.23)$ & $8(33.33)$ & \\
\hline Lower calyceal stone & $7(26.92)$ & $2(8.33)$ & \\
\hline Pelvic and calyceal stone & $4(15.38)$ & $4(16.67)$ & \\
\hline Upper calyceal stone & $1(3.85)$ & 0 & \\
\hline
\end{tabular}

GA: General anesthesia; RA: Regional anesthesia

patients with regional epidural anesthesia had less symptoms of nausea/ vomiting and more satisfaction with the surgery (Table-6).

\section{DISCUSSION}

Percutaneous nephrolithotomy is a minimally invasive surgery which is accepted for treating large renal and upper ureteric calculi (1-3). Several new techniques of PCNL such as mini-PCNL and tubeless PCNL were reported to decrease morbidity, analgesic requirement and duration of hospitalization (7). The method of anesthesia was reported to minimize morbidity following PCNL. The disadvantages of general anesthesia compared to regional spinal anesthe- 
sia are increased incidence of anaphylaxis due to multiple medication usage and more pulmonary, vascular, neurologic complications and problems associated with the endotracheal tube during the change of position from lithotomy to prone. Dur- ing supracostal puncture patients with PCNL under regional anesthesia can follow verbal commands and control respiration for prevention of pulmonary events (6). The advantages of spinal anesthesia compared to general anesthesia were

Table 2 - Access tract and success rate.

\begin{tabular}{|c|c|c|c|}
\hline Access, $n(\%)$ & & & \\
\hline Upper pole -supracostal & $14(53.85)$ & $12(50.00)$ & 0.441 \\
\hline Upper pole -subcostal & $7(26.92)$ & $4(16.67)$ & \\
\hline Middle pole & $1(3.85)$ & $4(16.67)$ & \\
\hline Lower pole & $4(15.38)$ & $4(16.67)$ & \\
\hline \multicolumn{4}{|l|}{ Operative time (hour) } \\
\hline mean(SD) & $78.85 \pm 19.71$ & $80.63 \pm 26.13$ & 0.786 \\
\hline \multicolumn{4}{|l|}{ Hospital stay (day) } \\
\hline mean(SD) & $5.46 \pm 2.08$ & $5.04 \pm 1.85$ & 0.456 \\
\hline Tubeless PCNL & $4(15.38)$ & $1(4.17)$ & 0.187 \\
\hline \multicolumn{4}{|l|}{ Success, n (\%) } \\
\hline Stone free & $14(53.80)$ & $17(70.00)$ & 0.400 \\
\hline CIRF & $7(27.00)$ & $2(20.00)$ & \\
\hline Retained stone & $5(19.2)$ & $2(10)$ & \\
\hline
\end{tabular}

GA: General anesthesia; RA: Regional anestesia; CIRF: Clinical insignificant residual fragment

Table 3 - Pre operative and post operative 24 hours $\mathrm{Hb} / \mathrm{Hct}$.

\begin{tabular}{lccc}
\hline Variable & GA $(\mathrm{n}=26)$ & $\mathrm{RA}(\mathrm{n}=24)$ & p-value \\
\hline Pre-op Hb (mg/dL) & $13.38(2.23)$ & $13.13(1.62)$ & 0.648 \\
Pre-op Hct (\%) & $40.06(5.78)$ & $40.05(4.58)$ & 0.992 \\
Hb 24 hours (mg/dL) & $11.45(2.01)$ & $11.13(1.84)$ & 0.552 \\
Hct 24 hours (\%) & $34.88(5.86)$ & $33.66(5.60)$ & 0.456 \\
\hline
\end{tabular}

GA: General anesthesia; RA: Regional anesthesia 
Table 4 - Post operative analog pain score (from 0 to 10) at 1,4,12,24,48 and 72 hours.

\begin{tabular}{llll}
\hline Variable & $\mathrm{GA}(\mathrm{n}=26)$ & $\mathrm{RA}(\mathrm{n}=24)$ & $\mathrm{p}$-value \\
\hline 1 Hour & $6.88(1.27)$ & $3.12(1.98)$ & $<0.001$ \\
4 Hours & $5.07(2.58)$ & $3.42(2.48)$ & 0.025 \\
12 Hours & $3.88(1.88)$ & $3.62(1.58)$ & 0.602 \\
24 Hours & $3.42(2.10)$ & $3.33(1.17)$ & 0.854 \\
48 Hours & $2.61(1.49)$ & $1.87(1.23)$ & 0.063 \\
72 Hours & $2.03(1.66)$ & $1.42(1.10)$ & 0.128 \\
\hline
\end{tabular}

GA: General anesthesia, RA: Regional anesthesia

Figure 1 - Post-operative pain score following PCNL with general anesthesia (GA) and regional (RA): $p<0.001$ at 1 hour and $p$ $=0.025$ at 4 hours.

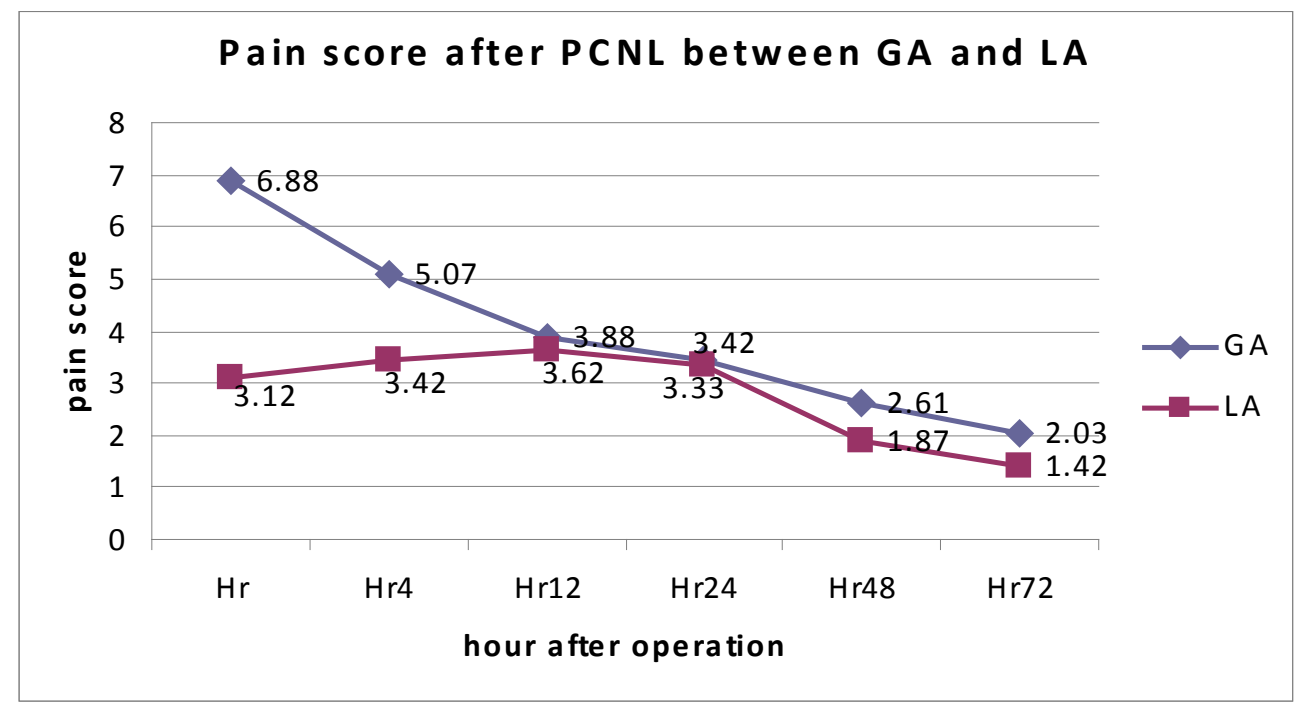

also demonstrated in other procedures such as radical retropubic prostatectomy (8) and unilateral total hip arthroplasty (9). Recently PCNL under regional spinal anesthesia was reported to gain benefits because regional spinal anesthesia achieves better postoperative quality of life due to earlier postoperative recovery but most reports were not part of the controlled study $(4,5)$.

Singh et al. (6) reported a prospective randomized study comparing PCNL under gen- eral anesthesia with PCNL under spinal epidural anesthesia. The study consisted of 32 patients of each group. VAS on the first postoperative day morning was $4.63 \pm 0.87$ at the epidural anesthesia group and $6.56 \pm 1.44$ at the general anesthesia group $(\mathrm{P}<0.0001)$. Mean analgesic (tramadol) requirement within 24 hours was lower in epidural anesthesia group $(100.00 \pm 10.00 \mathrm{mg}$ of epidural anesthesia: $158.6 \pm 22.84 \mathrm{mg}$ of general anesthesia, $\mathrm{p}<0.0001)$. Hospital stay was shorter 
Table 5 - Postoperative analgesic usage.

\begin{tabular}{lccc}
\hline Variable & GA $(\mathrm{n}=26)$ & $\mathrm{RA}(\mathrm{n}=24)$ & $\mathrm{p}$-value \\
\hline Morphine & & & \\
$\leq 10 \mathrm{mg}$ & $21(80.77)$ & $24(100)$ & 0.024 \\
$>11 \mathrm{mg}$ & $5(19.23)$ & 0 & \\
Paracetamol & & & \\
$\leq 1000 \mathrm{mg}$ & $22(84.62)$ & $20(83.33)$ & 0.902 \\
$>1000 \mathrm{mg}$ & $4(15.38)$ & $4(16.67)$ & \\
\hline
\end{tabular}

GA: General anesthesia; RA: Regional anesthesia

Table 6 - Adverse effects, complications and satisfaction.

\begin{tabular}{llll}
\hline Variable & $\mathrm{GA}(\mathrm{n}=26)$ & $\mathrm{RA}(\mathrm{n}=24)$ & $\mathrm{p}$-value \\
\hline Nausea and Vomiting & $6(23.07)$ & $1(4.19)$ & $\mathrm{P}=0.05$ \\
Hemorrhage need blood transfusion & & & \\
1 unit & $3(11.54)$ & $2(8.33)$ & 0.571 \\
2 unit & $1(3.84)$ & - & 0.600 \\
Pulmonary complication & $2(7.69)$ & $1(4.17)$ & 0.565 \\
Sepsis & 0 & $1(4.17)$ & \\
Satisfaction & & & 0.007 \\
1 & - & - & \\
2 & - & - & \\
3 & $2(7.69)$ & $1(4.17)$ & \\
4 & $20(76.92)$ & $9(37.50)$ & \\
5 & $4(15.38)$ & $14(58.33)$ & \\
\hline
\end{tabular}

GA: General anesthesia; RA: Regional anesthesia; Satisfactory (very unsatisfactory = 0 to very satisfactory $=5$ )

in epidural anesthesia group. Regional epidural anesthesia is equally effective and safe compared to the general anesthesia group.

Kuzgunbay et al. (4) compared the efficacy and safety between 37 patients who underwent PCNL under spinal epidural anesthesia and 45 patients under general anesthesia. Age, stone surface area, operative time, change of hemoglobin, hospital stay and stone free rates were no different between both groups. They concluded that PCNL under spinal regional anesthesia was as effective and safe as PCNL under general anesthesia. Karacalar et al. (5) reported the superior results of spinal epidural block compared 
to general anesthesia in some aspects such as patient satisfaction, less postoperative pain and shorter duration of post operative analgesic medication usage. Vomiting, itch, hypotension and bradycardia were not different between both groups but higher rate of nausea was found in general anesthesia group.

Andreoni et al. (10) reported the positive effect of a preoperative single dose of subarachnoid spinal anesthesia associated with general anesthesia in 9 patients who were treated by PCNL, compared to 11 patients who underwent general anesthesia alone. This technique can decrease postoperative pain, nauseous rates, postoperative analgesic medication usage and allows earlier ambulation.

Mehrabi et al. (11) evaluated 160 patients who were submitted to PCNL in the prone position under spinal anesthesia. 6 patients developed mild to moderate headache, dizziness and low back pain. 10 patients (6.3\%) received blood transfusion. Among these patients, 18 patients had hypotension controlled by intravenous ephedrine. Complications from the procedure were acceptable. Their conclusion was PCNL under spinal anesthesia is an alternative technique to general anesthesia. In contrast, hemodynamic instability during changing the patient position from supine to prone was not found in several reports (11-13).

In our study we used the epidural space between L 1-2 as the level for epidural puncture due to its safety followed by insertion of the tip of an epidural catheter to T-11 level. T- 6 level of anesthesia was achieved during the kidney operation. There are some advantages of regional epidural anesthesia group over general anesthesia including less nausea/vomiting $(p=0.005)$, less postoperative pain $(\mathrm{p}<0.01)$, less analgesic drugs usage $(p<0.024)$, and more patient satisfaction $(p<0.007)$. There are no differences between the two groups in postoperative hemoglobin, postoperative hematocrit, operative time, postoperative complication, success rate and hospital stays.

\section{CONCLUSIONS}

Percutaneous nephrolithotomy under regional anesthesia is as effective as PCNL under general anesthesia. The advantages of regional anesthesia over general anesthesia are higher patient satisfaction, less early postoperative pain and less analgesic usage without increasing complications.

\section{CONFLICT OF INTEREST}

None declared.

\section{REFERENCES}

1. Stening SG, Bourne S: Supracostal percutaneous nephrolithotomy for upper pole caliceal calculi. J Endourol. 1998; 12: 359-62.

2. Lojanapiwat B, Prasopsuk S: Upper-pole access for percutaneous nephrolithotomy: comparison of supracostal and infracostal approaches. J Endourol. 2006; 20: 491-4.

3. Jun-Ou J, Lojanapiwat B: Supracostal access: does it affect tubeless percutaneous nephrolithotomy efficacy and safety? Int Braz J Urol. 2010; 36: 171-6.

4. Kuzgunbay B, Turunc T, Akin S, Ergenoglu P, Aribogan A, Ozkardes $\mathrm{H}$ : Percutaneous nephrolithotomy under general versus combined spinal-epidural anesthesia. J Endourol. 2009; 23: 1835-8.

5. Karacalar S, Bilen CY, Sarihasan B, Sarikaya S: Spinal-epidural anesthesia versus general anesthesia in the management of percutaneous nephrolithotripsy. J Endourol. 2009; 23: 1591-7.

6. Singh V, Sinha RJ, Sankhwar SN, Malik A: A prospective randomized study comparing percutaneous nephrolithotomy under combined spinal-epidural anesthesia with percutaneous nephrolithotomy under general anesthesia. Urol Int. 2011; 87: 293-8.

7. Bellman GC, Davidoff R, Candela J, Gerspach J, Kurtz S, Stout L: Tubeless percutaneous renal surgery. J Urol. 1997; 157: 1578-82.

8. Salonia A, Suardi N, Crescenti A, Colombo R, Rigatti P, Montorsi F: General versus spinal anesthesia with different forms of sedation in patients undergoing radical retropubic prostatectomy: results of a prospective, randomized study. Int J Urol. 2006; 13: 1185-90.

9. Maurer SG, Chen AL, Hiebert R, Pereira GC, Di Cesare PE: Comparison of outcomes of using spinal versus general anesthesia in total hip arthroplasty. Am J Orthop (Belle Mead NJ). 2007; 36: E101-6.

10. Andreoni C, Olweny EO, Portis AJ, Sundaram CP, Monk T, Clayman RV: Effect of single-dose subarachnoid spinal anesthesia on pain and recovery after unilateral percutaneous nephrolithotomy. J Endourol. 2002; 16: 721-5. 
11. Mehrabi S, Karimzadeh Shirazi K: Results and complications of spinal anesthesia in percutaneous nephrolithotomy. Urol J. 2010; 7: 22-5.

12. Saied MM, Sonbul ZM, el-Kenawy M, Atallah MM: Spinal and interpleural bupivacaine for percutaneous nephrolithotomy. Middle East J Anesthesiol. 1991; 11: 259-64.
13. Singh I, Kumar A, Kumar P: "Ambulatory PCNL" (tubeless PCNL under regional anesthesia) -- a preliminary report of 10 cases. Int Urol Nephrol. 2005; 37: 35-7.

\section{Correspondence address:}

Dr. Bannakij Lojanapiwat Division of Urology Department of Surgery Chiang Mai University Chiang Mai, Thailand 50200 Fax: + 6653 945-154 E-mail: blojanap@mail.med.cmu.ac.th 